\title{
Defining Care and Residential Buildings with Respect to the Evacuation Capability of Occupants
}

\author{
GUNVOR HALLBERG
}

The Royal Institute of Technology

S-100 44 Stockholm, Sweden

\begin{abstract}
In 1989 the Swedish Building Code was revised. The traditional codes presenting technical solutions were replaced by a Planning and Building Act and Regulations for New Construction. The classification of activity in a building determines the designation of the building with respect to what fire regulations are applicable. The connection between the activity and the evacuation capability of the occupants should be examined, so that more consideration can be given to occupants when safety levels are set.
\end{abstract}

Dwellings for the elderly are chosen as examples of buildings presenting definition problems with regard to safety provisions. If the activity is clearly classed as either housing or care, then there is no uncertainty about the designation. Problems will arise when the safety level is to be adjusted to all intermediate forms between residential and institutional premises.

Use of a rating system for evacuation capability devised within a study of safety measures required in dwellings for the elderly makes it possible to adjust the safety level to the residents' evacuation capability. A proposal for the definition of residential buildings, care and housing units and hospital premises with respect to fire safety provisions is presented, as is a draft of safety features to be recommended in care housing.

KEYWORDS: Building codes, care housing, evacuation capability.

\section{INTRODUCTION}

At present, fire protection regulations differ for different kinds of buildings depending on what is going on in the building and also, to some extent, on the evacuation capability of the occupants. More consideration should, however, be given to the occupants' evacuation capability. That is, we should establish the connection between the activity in the building and 
the evacuation capability of the occupants in order to be able to predict this variable directly from the activity designation. That means we should find out the evacuation capability of the population taking part in the activity in various buildings. In this approach, the definition of the activity in a building would take account of the evacuation capability of occupants. As a result, the safety level of the building would be calibrated to the occupants' actual capabilities.

In 1989 the Swedish Building Code[1] was revised. Instead of the traditional codes presenting technical solutions there are now a Planning and Building Act[2] and Regulations for New Construction[3]. These Regulations contain one chapter concerning fire protection in residences and one concerning fire protection in care premises.

In residential buildings people are essentially supposed to be able to escape from the building by themselves. Very few persons are assumed to require assistance. The fire protection regulations are adjusted to this assumption. As an example, windows are approved of as alternative escape routes in residences. In hospital wards only a small number of patients are expected to manage on their own in a fire emergency. Consequently, special options required in hospitals include horizontal escape routes.

Thus, the fire protection regulations applicable to a building depend on how the activities in the building are described. If the activity is clearly classed as either housing or care, there is no problem as to which regulations would be applicable. Problems arise when the safety level is to be adjusted to all the intermediate forms between residential and institutional premises.

\section{INTERMEDIATE FORMS OF CARE AND HOUSING}

Dwellings for the elderly are examples of buildings presenting definition problems with respect to safety provisions. Sweden is not alone in encountering a problem in defining adequate safety levels for accommodation for the elderly.

In the USA the evaluation system FSES (A Fire Safety Evaluation System for Board and Care Homes) was developed by Nelson et al (1983)[4]. It calibrates the safety level with the residents' need of assisted escape. All kinds of buildings used as dwellings in combination with care are examined, from small dwellings units included in ordinary multi-family houses, to large residential facilities. The system consists of two subsystems, one for evaluating the residents' ability to escape and the other for estimating the safety features of the building. Four levels of evacuation difficulty are described, each requiring particular fire protection features. The calibration of safety level with evacuation capability means that, in general, the safety regulations for hotels and lodging houses are applicable to dwellings where the residents are expected to evacuate without assistance, however slowly, while safety regulations for hospitals are applicable to buildings where the residents are incapable of evacuating unassisted.

In Great Britain the regulations applicable to dwellings for the elderly depend on how such buildings are defined or designated. British Standard BS 5588 Part 8, the Fire Protection Code[5], deals with means of safe escape for any disabled people. However, it covers all 
buildings except single-family dwelling houses, flats and maisonettes. It is pointed out that 'buildings purpose-built for disabled people will usually be provided with means of escape that are more extensive than those recommended in this code'. In buildings requiring assisted escape, the Code stipulates evacuation in two stages (via refuge), assistance from staff or an evacuation elevator.

In the Canadian Building Code[6] institutional and residential buildings are dealt with separately. Certain facilities for the elderly are classified as institutional occupancies where the residents get continuous nursing and supervisory care, for instance in long term care units. In facilities classified as residential occupancies continuous nursing is not provided. Apartments, homes for the aged and lodging houses are classified as residential occupancies. In an institutional facility the residents are supposed to be dependent on assistance when escaping. Persons living in residential facilities should be able to evacuate unassisted. That is the same classification principle as in Sweden. In Canada, however, the fire safety needs of the resident population must already have been examined with respect to their capabilities and those of the staff and the facility at the planning stage. If a building has originally been designated as residential, it may only be used for this purpose, unless additional safety measures are provided. That means, I suppose, the residents had better move out when their evacuation capability deteriorates or that the building should be modified. A manual for fire safety in homes for the elderly[7] includes every kind of home from boarding homes to long term care units. However, no method for surveying 'residents profiles' is recommended.

In Sweden no judgement of the presumed occupants of a building is required. In blocks of service flats, for instance, the residents are assumed to be in good shape and capable of managing by themselves in a fire emergency. Possibly they are in relatively good health when moving in, but after some years their health and mobility will deteriorate and they will be in need of assistance from one or even two members of staff to escape.

In the Swedish Regulations for New Construction[3], Chapter Room, section Nursing Premises, a number of care facilities combining care with housing are enumerated. They include group-residential buildings for groups of mentally retarded, mentally ill or people with senile dementia. Nursing homes for care and rehabilitation of non-bedridden or physically disabled people are also mentioned. However, there is an important qualification. These are only designated as residential if not more than eight patients live within an apartment. If there are nine or more residents, then the building is classed as nursing premises, an institution.

\section{TOWARDS A RATING SYSTEM FOR EVACUATION CAPABILITY}

The character of the activity in a building and the number of occupants could hardly be the sole criteria for designating a building as residential or institutional. If you also want to take into consideration the future evacuation capability of the residents you need to know the general evacuation capacity of residents in that particular kind of dwelling.

The evacuation capacity of the residents in blocks of service flats for the elderly has been investigated[8]. It was found, that on the average nearly 50 per cent of the residents are not 
able to look after themselves during a fire. Nevertheless, such facilities are designated as dwellings in the Regulations for New Construction. However, the residents' evacuation capacity is not as good as expected in relation to the safety measures required. Consequently, the safety level is considerably lower in blocks of service flats than in ordinary dwelling houses.

There are examples of the opposite as well. In some facilities where the strict fire protection requirements for care premises are applied, they have come in conflict with the homelike atmosphere that is desirable in a care home. The requirement for escape routes with a width of $240 \mathrm{~cm}$ does not allow any seating furniture in corridors for the residents to rest on when moving to the restaurant, for instance. A homelike and cosy environment is considered to have a therapeutic significance within geriatric care. For that reason it is inappropriate that fire protection provisions should interfere with realization of a good nursing environment.

While working on the investigation of the safety level in blocks of service flats we have developed a rating system for evacuation capability. Using the system it will be practicable to find out whether a building would be classified as a dwelling, nursing premises or a combination of both as regards the required safety level. It is a matter of deciding the limits for residents" evacuation capability for different classes of buildings.

The object of rating the evacuation capability of residents is to become aware of the kind and amount of assistance required from staff during an evacuation. A resident's escape may be complicated by psychological and physical disabilities. There are certain relevant risk factors in an evacuation situation. The evaluation system constructed for residents in care dwellings illustrates five risk factors all affecting time required for evacuation. Those risk factors are chosen for the following reasons.

Mobility is significant for both horizontal and vertical movements. The ability to use stairs is an important distinguishing characteristic in the context of evacuation. The use of devices that facilitate movement, like wheelchairs and walkers, requires escape routes that meet certain specifications.

The pace of movements, i.e. horizontal movements with or without assistance, is relevant for calculating acceptable travel distances to escape routes. By means of information on the mobility and pace of movement, appropriate distances of both horizontal and vertical routes can be calculated. These figures may have to be modified by information on the factors which may affect them, like psychological problems and lack of response to the alarm signal.

Lack of response to alarm has significance for the design of alarm systems and the need for certain residents to be wakened personally. Risk of resistance relates to the time needed to effect evacuation, which is affected by delays caused by refusal to leave the flat or even by aggressive behaviour. Orientation difficulties affect the need for staff supervision to help residents to find the escape route and to remain at a designated location. These three psychological difficulties would all delay an evacuation. 
In order to collect information illustrating the existence and extent of these risk factors in various kinds of care housing a worksheet, reproduced below, could be used.

TABLE 1. A worksheet for rating residents

\begin{tabular}{|c|c|c|c|c|}
\hline This person & \multicolumn{4}{|c|}{ Check the most appropriate } \\
\hline is able to use stairs & yes & yes assisted & no & \\
\hline uses devices to aid movement & $\begin{array}{l}\text { crutches } \\
\text { walkers } \\
\end{array}$ & $\begin{array}{l}\text { drives } \\
\text { wheelchair }\end{array}$ & $\begin{array}{l}\text { needs assistar } \\
\text { with wheelch }\end{array}$ & \\
\hline moves at a pace which is & very slow & slow & rather quick & quick \\
\hline is hard to wake & yes & no & uncertain & \\
\hline is able to get out of bed alone & yes & no & & \\
\hline has orientation difficulties & yes & no & uncertain & \\
\hline $\begin{array}{l}\text { may resist evacuation or get } \\
\text { aggressive in an emergency }\end{array}$ & yes & no & mild risk & \\
\hline
\end{tabular}

The above worksheet is inspired by the FSES system for evaluation of evacuation difficulties [4]. That system has been tried in a home for elderly people in Sweden. It was found not directly applicable in a Swedish context. However, the FSES system does provide excellent guidance for devising such a system.

The evacuation capability of the occupants in a building used for care and housing would be rated for a representative sample of residents. Rating the residents in a ward, around a stair well or in a department which is representative for the establishment as a whole would be the most applicable method. The rating should be made by the staff. The same staff member does not need to rate all residents; it should be the one who knows each resident best who does the rating. The residents themselves would not be interviewed because of psychological problems. In this approach the rating is based on daily observations of the residents. The method conforms with the rating systems established for estimating peoples' ability to cope with different tasks of everyday life (ADL-Index) and with the FSES for rating evacuation difficulties.

The results of the rating, residents' evacuation capability, would be presented in two ways: their need for assistance from staff members during the evacuation and the percentage distribution of risk factors relevant to evacuation. As data are processed every rated person's data are transformed to a need of assistance. The need of assistance can be graded from 
'needing no assistance', 'needing a helping hand' (e.g. to wake some one or help people to find their way), 'needing assistance from one staff member for the whole evacuation' (e.g. to get out of bed, manage the wheelchair etc.) to 'needing assistance from two staff' (when the resident is unable to manage the stairs). If a person is rated to need assistance for more than one reason, the reason requiring help from most numbers of staff is decisive.

The evacuation capability of the residents is expressed as the percentage shares needing assistance from certain numbers of staff. A survey of evacuation capability of residents in a certain type of housing indicates which evacuation difficulties all residents rated are expected to experience. It also provides average figures for the residents in each structure studied. This enables us to study the difference between separate blocks of service flats or separate nursing homes and the characteristics of a special category, e.g. elderly people living in service flats or people with senile dementia in group-residential units. We can also calculate how the introduction of various technical solutions would affect the need for assistance.

So, as an example, by providing the possibility of horizontal evacuation to a protecting lobby or refuge, the need for assistance in care housing would be reduced. All residents unable to use stairs would be much safer. The majority of residents would still need help, but at most from one staff member (fully 30 per cent) or just a helping hand. Nearly 30 per cent of the residents in blocks of service flats would be able to manage on their own, according to the study of evacuation capability in such buildings.

The variable 'pace of movement' can be translated from 'very slow' etc to metres per second. Using data from three investigations [9], [10], [11] of walking speeds of elderly people and our own studies of peoples' movement behaviour[12], we have found that 'very slow 'corresponds to $0.7 \mathrm{~m} / \mathrm{second}$, 'slow' to $1.2 \mathrm{~m} / \mathrm{second}$, 'rather quick' to $1.5 \mathrm{~m} / \mathrm{second}$ and 'quick' to $2 \mathrm{~m} / \mathrm{second}$.

The worksheet described here is useful in more than one situation. The one already discussed is aimed at classifying the evacuation capacity in existing buildings. Another use of the form is as an aid in evacuation exercises. Residents are often too vulnerable to be able to take part in a fire drill. A series of already completed rating worksheets would be used as a sort of character or role description when staff members are acting as residents in an evacuation exercise. That method would make a vivid realization easier. It will also give a 'true' distribution of those needing assistance from one or two members of staff. At a fire drill in a new building, completed worksheets from an existing building with a population of the same kind could be used.

\section{A DEFINITION PROPOSAL}

Based on both the activity in and the evacuation capacity of occupants of residential buildings, of care and housing units and of hospital premises, the following definitions of these building types are proposed in this section. 
In buildings providing a combination of care and residential dwellings one or the other of these activities is emphasized: in ordinary dwellings and in blocks of service flats the stress is laid on the housing and care is provided on the conditions set by the housing context. If at least $75 \%$ of the residents are able to escape on their own, the building should be designated as a residential building. If more people than $25 \%$ but less than $75 \%$ of the residents are unable to use stairs, the building should be designated as a care and housing unit.

Even in cases where housing is subordinated to the care activity in such way that the environment and the performance of the dwellings are parts of the treatment, e.g. in nursing homes and group-residential buildings, the dwelling form should be designated care and housing unit. However, this is on condition that less than $75 \%$, of the residents are unable to use stairs. If more are unable to do so, the designation should be hospital premises.

In the blocks of service flats studied in the investigation made[8] the share 'unable to use stairs' varied from 25 to $75 \%$. In a pilot study made in a nursing home, the share 'unable to use stairs' was $47 \%$ of the residents. Accordingly, the definition of care and housing units, no matter which part of the activity mentioned is emphasized, should be: dwellings where between 25 and $75 \%$ of the residents are unable to escape on their own. This definition is also applicable to ordinary residential dwellings where people with evacuation difficulties have become 'too numerous', because 'staying on' in an ordinary dwelling is becoming more and more common.

In Sweden all people who want to 'stay on' in ordinary flats or one-family-houses even when in need of increasing assistance, are encouraged to do so, obtaining home help services and nursing care from mobile home-help assistants. Similar facilities are offered to residents in service flats, in blocks where communal facilities are provided in addition to care service related to residents' needs. In old people's homes residents have access to home help and nursing care from on-site staff. Nursing homes and long-term care units cater for the most debilitated patients, who require nursing, medical and terminal care.

In recent years people needing more mental than physical support are offered a collective form of housing in group-residential buildings. Such dwellings consist of large flats with a number (usually six) of residents living in private rooms with a lavatory of their own, or alternatively a group of traditional fully furnished flats assembled around a staircase or around rooms for social gatherings. Group residential housing is most applicable to the mentally retarded, people with senile dementia, and patients formerly treated in mental hospitals. More than $50 \%$ of the group-residential buildings are occupied by people with senile dementia today. The housing form is considered an alternative to nursing care in an institution for people needing supervisory care. The dwelling form is rather new. Local authorities and county councils are planning a rapid expansion and development.

\section{SAFETY REGULATIONS IN CARE HOUSING}

Altered fire protection provisions for care housing are proposed in a manual concerning safety 
features in facilities providing care in combination with housing[13]. The recommendations in the manual are based on results of analyses of evacuation capability. The manual is arranged according to the aim of fire protection measures related to the planning and building process.

TABLE 2. Safety measures in buildings where care and housing are combined

\begin{tabular}{|c|c|c|}
\hline $\begin{array}{l}\text { Aims of fire } \\
\text { protection measures }\end{array}$ & $\begin{array}{l}\text { Means of fire } \\
\text { protection }\end{array}$ & $\begin{array}{l}\text { Requirements expressed and fulfilled in the } \\
\text { planning and building process }\end{array}$ \\
\hline \multirow{4}{*}{ Fïre control } & \multirow{2}{*}{$\begin{array}{l}\text { Early } \\
\text { detection }\end{array}$} & At least one personnel 24 hours a day \\
\hline & & $\begin{array}{l}\text { Warning system } \\
\text { Communication system } \\
\text { Alarm system }\end{array}$ \\
\hline & \multirow{2}{*}{$\begin{array}{l}\text { Prevention of } \\
\text { spread of fire } \\
\text { and smoke }\end{array}$} & Compartmentation \\
\hline & & Fire fighting appliance \\
\hline \multirow{4}{*}{$\begin{array}{l}\text { Protection } \\
\text { of people }\end{array}$} & \multirow{2}{*}{$\begin{array}{l}\text { Evacuation } \\
\text { strategy }\end{array}$} & Horizontal evacuation \\
\hline & & Adapted means of egress \\
\hline & \multirow{2}{*}{$\begin{array}{l}\text { Provision } \\
\text { for rescue }\end{array}$} & Availability from inside the house \\
\hline & & Availability from the outside \\
\hline
\end{tabular}

Safety measures aim to control fire by early detection of a fire and prevention of fire spread. They also aim to protect people by safe means of escape and provision for rescue. The requirements are expressed at the program stage and specified at the planning stage of the building process. At the design stage technical preparations are made. They are realized at the construction stage. Management and use belong to the operation stage.

Both fire control and protection of people could be accomplished by technical as well as human measures. 'Early detection' could be achieved by detectors or by individuals using their sensory organs. In Sweden, not even in care housing, there exists no continuously present personnel responsible for management functions. That is the reason for the requirement for at least one personnel 24 hours a day.

Since staff are few, especially at night, a warning system is needed along with a twoway-communication system in order to find out if there is a real fire emergency and to tell the resident what to do and send in staff to rescue the person in danger. An alarm system is also needed to send for the fire brigade, but only when there actually is a fire. 
Many varieties of each of these kinds of systems are available on the market. A system that combines all three functions would be the most suitable. It would perform in the following way. Smoke detectors would be set out in every flat and carephones for two-way communication between the residents and the reception desk of the establishment would be installed. The detectors would produce a signal in the flat simultaneously with an alarm at the reception. The address of the flat in danger would appear in the display of the paging devices of the staff. The alarm would not be transmitted directly to the fire station. It would remain within the building until the nature of the fire threat has been checked out. Then it would be passed over to the fire station. The two-way communication system would be opened automatically to the flat where the detector is activated. Such a combination of warning, communication and alarm systems would be suitable in all kinds of residential buildings occupied by people who cannot cope with the safety problems on their own.

To prevent fire from spreading there should be compartmentation and fire fighting appliances. Compartmentation means that the floor is divided into some sections which are separated by walls and doors able to resist fire for a certain period of time.

For the protection of people, especially people with motor disabilities, the means of horizontal evacuation is important. Each flat constitutes a fire compartment. Means of horizontal evacuation implies more than one fire compartment on each floor in addition to the flats. In the event of an emergency, residents should move to the next fire compartment in the lobby outside their flat. They are supposed to wait there for instructions to continue the evacuation or to return to their flats. Providing additional compartments on each floor is not a suitable approach in all types of buildings. As an alternative, evacuation in two stages via a protection lobby or refuge might be a solution. A temporary fire resistant refuge for use by disabled people has been applied in recent technical literature in UK and USA, for example.

Adapted means of egress in the table above, means staircases designed to simplify assistance to a person coming downstairs, for instance. It also means fluorescent paint to assist orientation towards exits. 'Provision for rescue' concerns availability from inside the building as well as from outside. That requires access to keys or automatic unlocking for staff when smoke detectors are activated.

Staff training in evacuation planning and techniques is important. Evacuation exercises using the training aids mentioned earlier are necessary. New employed staff members should be fully informed of how the internal warning system functions. Regular control of combinations of technical and human functions is needed. A floor agent, a person responsible for the fire safety functions in the building, would be elected.

If these recommendations are followed the safety features concerning fire control as well as protection of people would be adequate and the safety level in care housing would be calibrated to the evacuation capability of the residents. 


\section{REFERENCES}

1. Swedish Building Code,SBN, "Fire Protection". (Ch. 37), Nat. Swed. Board of Phs. Planning and Building, Stockholm, Sweden, 1980.

2. Swedish Planning and Building Act,BFS 1987:10, Nat. Board of Housing, Building and Planning, Karlskrona, Sweden, 1988.

3. Swedish Regulations for New Construction, BFS 1988:18, Nat. Board of Housing, Building and Planning, Karlskrona, Sweden, 1989.

4. Nelson, H.E., Levin, B.M., Shibe, A.J., Paulsen, R.L., Alvord, D.M. and Thorne, S.D., A Fire Safety Evaluation System for Board and Care Homes, Nat. Bur. Standards, Washington DC., USA, 1983.

5. BSI. Fire precautions in the design and construction of buildings, Pt. 8, Code of practice for means of escape for disabled people, BSI, London, UK, 1988.

6. Associate Committee on the National Building Code, National building code of Canada, Ottawa, National Research Council of Canada, 1980.

7. Richardson, J.K.( ed.), Manual for Fire Safety in Homes for the Elderly, Ottawa, National Research Council of Canada, 1983.

8. Hallberg, G., "Evacuation Safety in Dwellings for the Elderly", in Safety in the Built Environment,ed. J.D. Sime, pp. 103-115, E.\& F.N. Spon., London, 1988.

9. Aniansson, A., Mellström, D., Rundgren, $\AA$. and Svanborg, A., "Elderlys' Accidents an analysis of some factors behind them" (in Swedish). Report from the population study '70-years-olds in Gothenburg', Läkartidningen,42/80 pp 3755-3769, 1980.

10. Dahlstedt, S., Slow Pedestrians - Pensioners' walking speeds and walking habits (in Swedish), Swedish Council for Building Research, Stockholm, Sweden, 1978.

11. Wilson, J.R. and Rennie, A.M., Elderly Pedestrians and Road Safety,Institute for Consumer Ergonomics, University of Technology, Loughborough, UK, 1980.

12. Hallberg, G. and Nyberg, M., Movement behaviour, movement pattern and space requirement,(in Swedish), Report R13:1981, Dep. of Building Function Analysis, School of Architecture, Royal Institute of Technoplogy, Stockholm, Sweden, 1981.

13. Hallberg. G., Planning for Fire Safety in Care Housing,(in Swedish), Report R4:1990, Dep. of Building Function Analysis, School of Architecture, Royal Institute of Technology, Stockholm, Sweden, 1990. 